\title{
Fuzzy Analytical Hierarchical Process and Spatially Explicit Uncertainty Analysis Approach for Multiple Forest Fire Risk Mapping
}

\author{
Bakhtiar Feizizadeh $^{1}$, Khalil Omrani ${ }^{1}$ and Fereidon Babaei Aghdam ${ }^{2}$ \\ ${ }^{1}$ Dep. of Remote Sensing and GIS, University of Tabriz, Iran·feizizadeh@tabrizu.ac.ir \\ ${ }^{2}$ Dep. of Geography and Urban Planning, University of Tabriz, Iran
}

Full paper double blind review

\begin{abstract}
Uncertainty is associated with GIS- Multi Criteria Decision Analysis (GIS-MCDA) when applied to disaster modeling. Technically speaking, GIS-MCDA model outcomes are prone to multiple types of uncertainty and error. In order to minimize the inherent uncertainty, within this research we introduced a novel approach of spatial explicit uncertainty and sensitivity analysis for GIS-MCDA models. This novel approach is developed based on early works published by FEZIZADEH et al. 2014a, 2014b and makes use the capability of Fuzzy-Analytical Hierarchical Process (FAHP), Monte Carlo Simulation (MCS) and Variance based Global Sensitivity Analysis (GSA). This approach was examined on forest fire susceptibility mapping. The methodology contains of three different phases. Within the first step, weights were computed to express the relative importance of factors (criteria) for forest fire susceptibility through FAHP. In the second step, the uncertainty and sensitivity of Forest Fire Risk Mapping was analyzed as a function of weights using MSC and GSA. Finally, the results were validated against the forest fire inventory database. The results indicate that further improvement in the accuracy of GIS-based MCDA can be achieved by applying the proposed sensitivity uncertainty analysis approach.
\end{abstract}

\section{Introduction}

Multi-Criteria Decision Analysis (MCDA) techniques have become increasingly widespread in strategic environmental and future hazard prediction decision making (MOSADEGHI et al. 2009). Combining GIS and MCDA provides powerful approach for Forest Fire Risk Mapping (FFRM). The Fuzzy Analytical Hierarchical Process (FAHP) is one of the most commonly MCDA techniques has been incorporated into GIS-based suitability procedures. FAHP is an integrated approach of fuzzy logic and Analytical Hierarchical Process (AHP) which retains many of the advantages enjoyed by conventional AHPs. The FAHP handles multiple criteria and combinations of qualitative and quantitative data. However, all decision making approaches involving natural systems face a number of uncertainties ranging from ambiguity in defining problems and goals to uncertainty in data and models (REFSGAARD et al. 2007). In addition, uncertainty in GIS-MCDA may comes from various sources such as uncertainty of dataset, criteria weights or model parameters (MALCZEWSKI 2006). Technically speaking, criteria weights are often the greatest contributor to contro-

GI_Forum - Journal for Geographic Information Science, 1-2015.

(c) Herbert Wichmann Verlag, VDE VERLAG GMBH, Berlin/Offenbach. ISBN 978-3-87907-558-4.

(c) ÖAW Verlag, Wien. ISSN 2308-1708, doi:10.1553/giscience2015s72. 
versy and uncertainty (CHEN \& ZHU 2010, FEIZIZADEH et al. 2012). Even small changes in decision weights and methods may have a significant impact on the rank ordering of the criteria. Based on this statement, it is reasonable to mention that the results of GIS-MCDA sometimes lead to inaccurate outcomes and undesirable consequences (Feizizadeh \& Blaschke 2014). In order to reduce the chance of error in GIS-MCDA methods, uncertainty analysis is a process that leads to assess the reliability of MCDA's results in both quantitative and qualitative approaches (FEIZIZADEH \& BLASCHKE 2014). Although a massive amount of papers on susceptibility models were published in the last two decades, only few of them have dealt with the evaluation of prediction capability, robustness, and sensitivity (MELCHIORRE et al. 2011). The FFRM process developed in current research uses a wellestablished GIS-MCDA methods including: FAHP, Monte Carlo Simulation (MCS) and variance based Global Sensitivity Analysis (GSA) to compute the inherent uncertainty and sensitivity analysis for minimizing the chance of error in GIS-MCDA.

\section{Study Area and Datasets}

The study area was Ramsar Forest which is located in the western part of Mazandaran Province, Iran (see figure 1). The study site covers an area about 196.8 Hectare. Forest fire is common risk in this area, and between the years 2000 and 2012, totally 12 serious forest fire events were reported. Some of these events affected more than 5 hectare of the study area. Obviously such events resulted in important biodiversity loss (MNR 2012). Within this research we wanted to produce FFRM for identifying the potential areas of forest fire risk within the Ramsar Forest. For this goal, relevant criteria of FFRM were considered. In selection of relevant criteria it is necessary to be considered that the set of criteria should adequately represent the problem domain and contribute towards the ultimate objective (TENERELLI \& CARVER 2012). Within this study, three main criteria were selected including: topography, anthropogenic and forest vegetation property. In doing so, we used slope, aspect and elevation as topographic parameters (HEARN et al. 2001). In terms of anthropogenic factors we aimed to employ that these factors which are more correlated to the manmade/accidental forest fire. Therefore we considered distance to settlements and roads as an effective factors which make frost prone to fire (ZAREKAR 2012). Based on this assumption, seven indices were selected as forest vegetation property which are included: a) The Moisture Stress Index (CHAmpagne et al. 2001), b) The Carotenoid Reflectance Index (GITELSON et al. 2002), c) The Normalized Difference Lignin Index (SERRANO et al. 2002), d) The Normalized Difference Nitrogen Index (SERRANO et al. 2002), e) Plant Senescence Reflectance Index, f) The Red Edge Normalized Difference Vegetation Index (GITELSON \& MERZLYAK 1994) and g) The Normalized Difference Water Index (GAO 1995). 


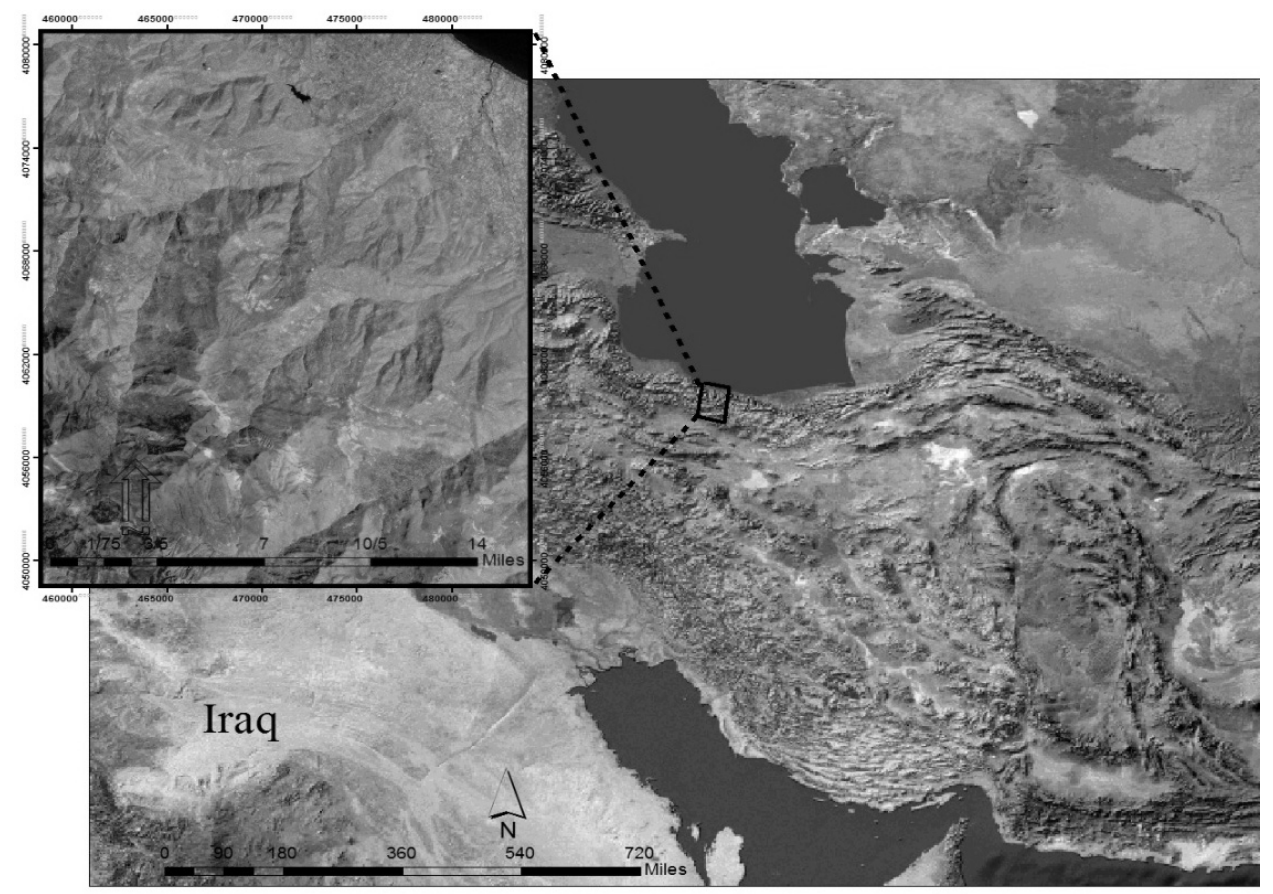

Fig. 1: Location of the study area

\section{Methodology Scheme}

The research methodology is based on the concept of evaluating the uncertainty of GISMCDA for FFRM through the spatial explicit approaches. The Methodology of research consists three different essential steps. The proposed sensitivity and uncertainty analysis is based on the spatially explicit simulation of error propagation. For this to goal, we employ MCS and variance based GSA for assessing the uncertain weight space. Finally validation process performed by using the forest fire inventory database. In this phase we aimed to compute the accuracy of FFRM and investigate the improved accuracy of FAHP by means of applying sensitive and uncertainty analysis.

\subsection{Criteria Weighting and Fuzzy Membership Functions}

Criterion weights are the weights assigned to the objective and attribute maps (FEIZIZADEH \& BLASCHKE 2012, 2013). In this stage, the effects of each criteria to the susceptibility of forest fire were determined by evaluating the preferences of the criterion to the FFRM. In order to assign the relative importance of the predictor variables and produce FFRMs, the first step was constructing a pairwise comparison matrix using the previous knowledge of goodness-of-fit. The standardized predictor variable values were aggregated based on the weights were derived from AHP and FAHP methods. In order to obtain criteria weights, the pairwise comparison matrixes of AHP and FAHP were constructed by employing 12 rele- 
vant criteria (see table 1). These pairwise comparison matrixes were formed using initial simple ranks obtained from export knowledge. In order to calculate the FAHP weights, FAHP based pairwise comparison matrix was prepared based on TFNs (minimum, mean, maximum values as $m_{1}, m_{2}, m_{3}$ ). Table 1 shows results of applying FAHP for calculating criteria weighting. In the application of the AHP and FAHP methods it is important that the weights derived from a pairwise comparison matrix are consistent. Therefore, one of the strengths of FAHP is that it allows for inconsistent relationships while, at the same time, providing a Consistency Ratio (CR) as an indicator of the degree of consistency or inconsistency (The CR is used to indicate the likelihood that the matrix judgements were generated randomly(FEIZIZADEH \& BLASCHKE 2012). In our research, the CR value was computed to be about 0.021 . This value clearly indicates that the comparisons of characteristics were perfectly consistent and that the relative weights were appropriate to be used for producing FFRM.

\subsection{Application of FMFs}

In the context of FFRM based on FAHP, the susceptibility values should lie between 0 and 1. Accordingly, 0 is assigned as none susceptible areas while 1 indicates the high susceptible areas. So far, there is no optimal method for choosing the most appropriate FMFs and their respective parameters (FEIZIZADEH et al. 2014a). Generally these values are selected according to the preferences of the decision makers. In this process, sigmoidal (s-shaped) fuzzy membership functions (i.e., monotonically increasing and monotonically decreasing) and user-defined fuzzy membership functions along with crisp membership functions can be applied for specifying each FFRM criteria (FEIZIZADEH et al. 2014a). The sigmoidal membership function is likely the most commonly used function in fuzzy set theory (EASTMAN 2004, LIU et al. 2004), and provides a gradual variation from non-membership 0 to complete membership 1, whereas it is sometimes inevitable to use user-defined FMFs or crisp membership functions (FEIZIZADEH et al. 2013, 2014a). In terms of AHP method, each related fuzzy membership functions are divided into 10 equal intervals. In other words, apart from starting and end points of each fuzzy membership functions, the area under the curve which is greater than 0 and less than 1 is divided into eight equal-sized intervals. Nevertheless, all applied functions of FFRM criteria outputs of each parameter were classified into groups of FFRM.

\subsection{Applying Monte Carlo Simulation and GSA on FAHP}

The uncertainty of attribute values and weights can be represented as a probability distribution or a confidence interval (FEIZIZADEH et al. 2014b). Accordingly, in order to deal with inherent uncertainty associated with FAHP, we applied MCS and GSA approaches for minimizing uncertainty of FAHP. Simulation is one of the most appropriate approaches to analyse uncertainty propagation through a GIS model, without knowing the functional form of the errors (TENERELLI \& CARVER 2012). The FAHP-MCS approach takes the probabilistic characterization of the pairwise comparisons into account (HAHN 2003; FEIZIZADEH et al. 2014b). This approach is based on the association with probability distributions which is enough to confirm that one alternative is preferred to another (in the sense of maximizing expected utility)which is provided that certain constraints on the underlying utility function are satisfied (DURBACH \& STEWART 2012). Within this research two essential steps were 
followed for applying MCS and GSA on FAHP. In the first step, statistical analysis ability of MCS used to perform the uncertainty analysis associated with FAHP weights. For this goal, our research methodology makes use of the concept of FAHP-MCS, where we consider the criteria weights derived from the FAHP pairwise matrix for the uncertainty analysis using MCS. We introduce uncertainty in the algorithm by creating uniform distributions based on the elements of random pairwise. The MCS was performed on FAHP weights, were presented in table 1 . The simulation was run $\mathrm{N}$ times to determine uncertain weights. It has to be mention that $\mathrm{N}$ is number of simulation which varies from 100 to 10000 according to the computational load, the complexity of the model, and the desired accuracy (FEIZIZADEH et al. 2014b). In the second step, the variance-based GSA was applied to quantitatively determine the weights that have the most influence on the model output. Within this step we aimed to determine first order (S), total effect (ST) between criteria.

Table 1: Pairwise comparison matrix for dataset layers of forest fire analysis

\begin{tabular}{|c|c|c|c|c|c|c|c|c|c|c|c|c|c|}
\hline Factors & (1) & (2) & (3) & (4) & (5) & (6) & (7) & (8) & (9) & (10) & (11) & (12) & $\begin{array}{l}\text { Eigen } \\
\text { value }\end{array}$ \\
\hline (1) PSRI & 1 & & & & & & & & & & & & 0.0355 \\
\hline (2) Rendvi & 1 & 1 & & & & & & & & & & & 0.0355 \\
\hline (3) NDNI & 2 & 2 & 1 & & & & & & & & & & 0.0628 \\
\hline (4) NDLI & 2 & 2 & 1 & 1 & & & & & & & & & 0.0640 \\
\hline (5) MSI & 5 & 5 & 4 & 4 & 1 & & & & & & & & 0.1724 \\
\hline $\begin{array}{l}\text { (6) Distance to } \\
\text { Settlement }\end{array}$ & 3 & 3 & 2 & 2 & $1 / 2$ & 1 & & & & & & & 0.1078 \\
\hline $\begin{array}{l}\text { (7) Distance to } \\
\text { Road }\end{array}$ & 4 & 4 & 3 & 3 & 1 & 2 & 1 & & & & & & 0.1657 \\
\hline (8) Elevation & 2 & 2 & 1 & 1 & $1 / 2$ & $1 / 2$ & $1 / 3$ & 1 & & & & & 0.0674 \\
\hline (9) Slope & 1 & 1 & $1 / 2$ & $1 / 2$ & $1 / 3$ & $1 / 3$ & $1 / 4$ & $1 / 2$ & 1 & & & & 0.0414 \\
\hline (10) Aspect & 1 & 1 & $1 / 2$ & $1 / 2$ & $1 / 3$ & $1 / 3$ & $1 / 4$ & $1 / 2$ & 1 & 1 & & & 0.0414 \\
\hline (11) NDWI & 5 & 5 & 4 & 3 & 1 & 2 & 1 & 3 & 2 & 2 & 1 & & 0.1691 \\
\hline (12) CRI & 1 & 1 & $1 / 2$ & $1 / 2$ & $1 / 4$ & $1 / 3$ & $1 / 3$ & $1 / 2$ & 1 & 1 & $1 / 5$ & 1 & 0.0372 \\
\hline
\end{tabular}

Table 2 shows the results of GSA for FFRM. Interpretation of these indices provides information about the important factors in the overall ranking options (FEIZIZADEH et al. 2014b). According to results of sensitivity and uncertainty analysis slope is identified to be as most important criteria for FFRM while the NDNI index turned out as less important criteria. 
Table 2: Results of GSA

\begin{tabular}{|l|l|l|l|l|l|l|}
\hline Factor & $\begin{array}{l}\text { Reference } \\
\text { weights }\end{array}$ & $\begin{array}{l}\text { Maximum } \\
\text { weights }\end{array}$ & $\mathrm{S}$ & ST & S\% & ST \% \\
\hline Slope & 0.041 & 0.051 & 0.275 & 0.592 & 27.5 & 24.3 \\
\hline Distance to Road & 0.167 & 0.167 & -0.007 & 0.24 & -0.7 & 9.3 \\
\hline Distance to Settlements & 0.107 & 0.117 & 0.031 & 0.241 & 3.1 & 3.1 \\
\hline MSI index & 0.172 & 0.182 & -0.003 & 0.252 & -0.3 & 9.8 \\
\hline NDLI index & 0.040 & 0.050 & 0.101 & 0.262 & 10.1 & 10.2 \\
\hline NDNI index & 0.062 & 0.062 & 0 & 0 & 0 & 0 \\
\hline NDWI index & 0.169 & 0.179 & 0.015 & 0.136 & 1.5 & 5.3 \\
\hline PSRI index & 0.035 & 0.045 & -0.015 & 0.236 & -1.5 & 9.2 \\
\hline RENDVI index & 0.035 & 0.045 & 0.074 & 0.326 & 7.4 & 12.7 \\
\hline CRI index & 0.037 & 0.047 & 0.0032 & 0.08 & 0.78 & 1.2 \\
\hline Elevation & 0.067 & 0.077 & 0.001 & 0.05 & 0.1 & 2 \\
\hline Aspect & 0.041 & 0.051 & 0.063 & 0.204 & 6.3 & 7.9 \\
\hline
\end{tabular}

\section{Results}

In order to produce FFRM maps, forest fire risk maps were obtained based on two approaches. The conventional approach was based on the application of the FAHP as standard methodology of GIS-MCDA for developing FFRM. While, the second approach was a proposed approach of GSA-FAHP for employing FAHP under sensitivity and uncertainty analysis. In doing so, the FFRM maps were produced using the results of two group of weights for both of the FAHP and GSA-FAHP approaches (see Table 1 for FAHP and Table 2 for GSA-FAHP). Figure 2 represents results of FFRM for FAHP and GSA-FAHP. In order to derive FFRMs, first result of FAHP was used and all criteria were combined for producing FFRM (Fig. 2a). Secondly, in the following computation of a baseline FFRMs, an alternative of forest fire risk map was computed by applying revised weights which were derived from GSA-FAHP (See Fig. 2b). Finally, the validation process was performed for examining the efficacy of each method. Within this step we aimed to examine and test the accuracy of the FAHP and GSA-FAHP against known forest fire locations occurred in the study area. The results of this comparison indicated that the very high susceptible category of FAHP map covers about $33 \%$ of known forest fire locations, while the high and moderate categories of this map together covered about $25 \%$ of known forest fire locations. The low susceptibility category also covered about $16 \%$ of known forest fire events. In terms of validation process for GSA-FAHP, results indicated the significant improvement in accuracy of FAHP when very high susceptible category of GSA-FAHP covered about $58 \%$ of known forest fire locations. The high and moderate categories of this map indicated the accuracy of $25 \%$ and $0.08 \%$ respectively. 

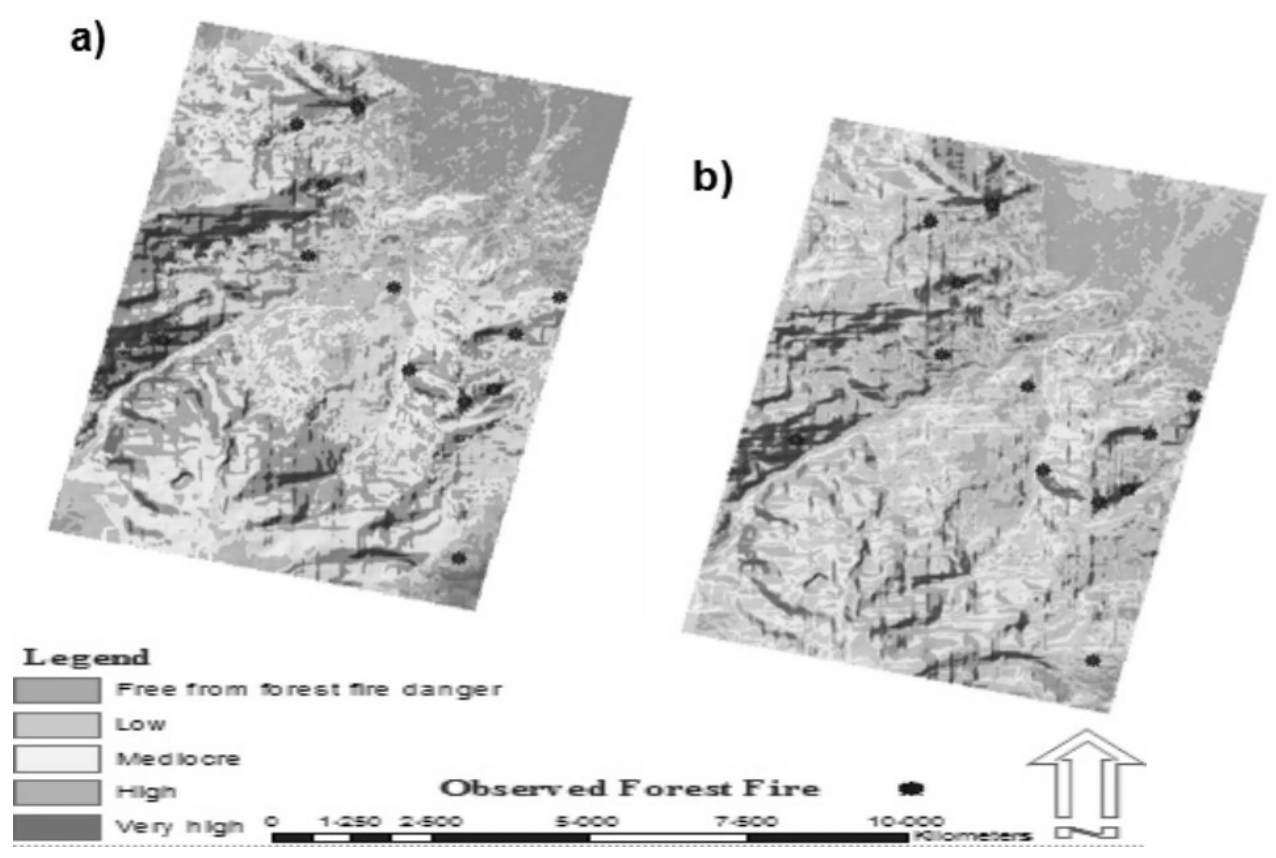

Fig. 2: Results of FFRM, a) FFRM produced based on FAHP and b) FFRM produced based on GSA-FAHP

\section{Conclusion and Outlook}

According to results of this research, GIS-MCDA is indeed provides powerful methodology for spatial analysis and environmental modelling. However, due to the large amount of parameters and the heterogeneity of data sources, the uncertainty of the results is typically unclear (FEIZIZADEH \& BLASCHKE 2014). Within this research we aimed to introduce a novel approach for employing FAHP under concept of sensitivity and uncertainty analysis. Our initial results demonstrated applying sensitivity and uncertainty analysis on FAHP based on GIS-MCDA leads to improve accuracy of results significantly. It also turned out that even small changes in decision weights and methods may have a significant impact on the rank ordering of the criteria and may subsequently change the results (FEIZIZADEH \& BLASCHKE 2012). In this paper, we focused on the applying of spatially explicit approach for sensitive and uncertainty analysis of GIS-MCDA, integrating FAHP and MCS-GSA for optimization algorithm and assessing the certainty of outcomes. As results clearly indicated, further improvement in accuracy of GIS-based MCDA can be achieved by employing the MCS method and accordingly integrating GSA for sensitivity analysis of the weights derived from FAHP. This study demonstrates the importance of spatially explicit approach for incorporating GIS and MCDA models. 


\section{References}

Champagne, C., Pattey, E., Bannari. A. \& Stratchan, I. B. (2001), Mapping Crop Water Status: Issues of Scale in the Detection of Crop Water Stress Using Hyperspectral Indices. In: Proceedings of the 8th International Symposium on Physical Measurements and Signatures in Remote Sensing, Aussois, France, 79-84.

CHEN, J. \& ZHU, Q. (2010), Uncertainty and decision strategy analysis of GIS-based ordered weighted averaging method. In: IEEE 2010 International conference on information, networking and automation (ICINA), 375-379. ISBN 978-1-4244-8106-4.

DURBACH, I. N. \& STEWART, T. J. (2012), Modeling uncertainty in multi-criteria decision analysis. European Journal of Operational Research, 223, 1-14.

FEIzizadeH, B. \& BlaschKe, T. (2012), Uncertainty and Decision Strategy Analysis of GIS-based Ordered Weighted Averaging Method for Landslide susceptibility mapping in Urmia lake basin, Iran. International conference of GIScience 2012, Columbus, Ohio, USA, September, 18-21, 2012.

FEIzIZADEH, B., BLASCHKE, T. \& NAZMFAR, H. (2012), GIS-based Ordered Weighted Averaging and Dempster Shafer Methods for Landslide Susceptibility Mapping in Urmia lake Basin, Iran, International Journal of Digital Earth. DOI:10.1080/17538947.2012.749950.

FEIZIZADEH, B. \& BLASCHKE, T. (2013), GIS-multicriteria decision analysis for landslide susceptibility mapping: comparing three methods for the Urmia Lake Basin, Iran. Nat.Hazards, 65, 2105-2128.

FeIzIZAdeh, B., BlaschKe,T. \& Shadman Roodposhti, M. (2013), Integration of GIS based Fuzzy set theory and Multicriteria Evaluation methods for Landslide Susceptibility Mapping. International Journal of Geoinformatic, 9 (3), 49-57.

FEIZIZADEH, B. \& BlASCHKE, T. (2014), Uncertainty analysis of GIS-Multicriteria based landslide susceptibility mapping. International Journal of Geographic Information Science, 28 (3), 610-638.

FEIzIZADEH, B., JANKOWSKI, P. \& BlaschKe, T. (2014a), A GIS based Spatially-explicit Sensitivity and Uncertainty Analysis Approach for Multi-Criteria Decision Analysis. Computers and Geosciences, 84, 81-95.

Feizizadeh, B., Shadman Roodposhti, M., Jankowski, P. \& Blaschke, T. (2014b), GIS-Based Extend Fuzzy Multi-Criteria Evaluation for Landslide Susceptibility Mapping. Computers and Geosciences, 64, 81-95.

EASTMAN, J. R. (2004), IDRISI Kilimanjaro: Guide to GIS and Image Processing. Clark University, Worcester, Clark Labs.

GAO, B. C. (1995), Normalized Difference Water Index for Remote Sensing of Vegetation Liquid Water from Space. In: Proceedings of SPIE, 2480, 225-236.

Gitelson, A. A., Zur, Y., Chivkunova, O. B. \& Merzlyak. M. N. (2002), Assessing Carotenoid Content in Plant Leaves with Reflectance Spectroscopy. Photochemistry and Photobiology, 75, 272-281.

Gitelson, A. A. \& MerzlyaK, M. N. (1994), Spectral Reflectance Changes Associated with Autumn Senescence of Aesculus Hippocastanum L. and Acer Platanoides L. Leaves. Spectral Features and Relation to Chlorophyll Estimation. Journal of Plant Physiology, 143, 286-292. 
Hearn, P., J. R., Hare, T., Schruben, P., Sherrill, D., LaMar, C. \& Tsushima, P. (2001), Global GIS database: digitalatlas of South Asia. US: Geological Survey. Digital Data Series DDS-62-C.

HAHN, E. D. (2003), Decision making with uncertain judgments: a stochastic formulation of the analytic hierarchy process. Journal of the Decision Sciences Institute, 34 (3), 443-466.

LiU, J. G., MAson, P., Hilton, F \& LeE, H. (2004), Detection of rapid erosion in SE Spain: a GIS approach based on ERS SAR coherence imagery. Photogramm. Eng. Remote Sens., 70 (10), 1185-1197.

Melchiorre, C., Castellanos Abella, E. A., van Westen, C. J. \& Matteucci, M. (2011), Evaluation of prediction capability, robustness, and sensitivity in non-linear landslide susceptibility models, Guanta namo, Cuba. Computers \& Geosciences, 37, 410-425.

MALCZEWSKI, J. (2006), GIS-based multicriteria decision analysis: a survey of literature. International Journal of Geographical Information Science, 20 (7), 703-726.

MNR, Ministry of NATURAl Resources, MAZANDARAN Province. (2012), Forest fire event report. Iran.

Mosadeghi, R., Tomlinson, R., Mirfenderesk, H. \& WARnKEN, J. (2009), Coastal Management Issues in Queensland and Application of the Multi-Criteria Decision Making Techniques. Journal of coastal research, SI56, 1252-1256.

RefsgaArd, J. C., VAn Der Sluiss, J. P., Lajer Højberg, A. \& VAnrolleghem, P. A. (2007), Uncertainty in the environmental modelling process A framework and guidance. Environmental modelling \& software, 22 (11), 1543-1556.

Serrano, L., Penuelas, J. \& Ustin, S. L (2002), Remote Sensing of Nitrogen and Lignin in Mediterranean Vegetation from AVIRIS Data: Decomposing Biochemical from Structural Signals. Remote Sensing of Environment. 81, 355-364.

TENERELLI, P. \& CARVER, S. (2012), Multi-criteria, multi-objective and uncertainty analysis for agro-energy spatial modeling. Applied Geography, 32, 724-736.

Zareka, A. R., VAhidi, H., KaZemi ZAMani, B., GHorbani, S. \& Jafari, H. (2012), Forest fire hazard mapping using fuzzy AHP and GIS, study area: Gillan province of Iran, International Journal on "Technical and Physical Problems of Engineering" (IJTPE) 